EGU21-13029

EGU General Assembly 2021

(c) Author(s) 2021. This work is distributed under

the Creative Commons Attribution 4.0 License.

\title{
Green roof effects on the rainwater response in the Mediterranean area: first results of a Sicilian case study
}

\author{
Dario Pumo, Antonio Francipane, Francesco Alongi, and Leonardo Noto \\ Dipartimento di Ingegneria, Università di Palermo, Palermo, Italy (dario.pumo@unipa.it)
}

Over the last decades, we have been witnessing an increasing frequency of urban floods often attributed to the interaction between intensification of rainfall extremes due to climate change and increasing urbanization. Consequently, many studies have been trying to propose different new alternatives to mitigate ground effects of ever more frequent and severe extreme rainfall events in a context of growing urbanization, such as rain gardens, green roofs, permeable parking lots, etc., which are commonly referred to as green infrastructures.

With this regard, one of the most promising mitigation solutions is represented by multilayer green roofs. These systems, coupling classical green roofs with a rainwater harvesting system, results in a high capacity in retaining rainwater, thus improving the potential effects acted by classical green roofs on pluvial floods mitigation. These systems are particularly suited for applications in semi-arid climate, where a fraction of the rainwater can be detained during the more severe rainfall events, significantly reducing the pressure on drainage systems, and released in a later moment or reused, for instance, to sustain the vegetation during driest periods.

This study describes a multilayer green roof installed at the Department of Engineering of the University of Palermo (Sicily, Italy) and its preliminary results on its capacity to reduce the pressure of rainfall events on drainage systems in a Mediterranean context. The green roof has an extension of almost $35 \mathrm{~m}^{2}$ and is made of three different areas with different soil thickness (a mixture of volcanic material) and different Mediterranean vegetation. The green roof is equipped with multiple sensors to monitor the water level in the storage layer, soil water content, air and water temperature, and rainfall. Besides, a weighted rain gauge, a disdrometer, and a meteorological station for the collection of meteorological data are available as well.

An equal size classical roof area bordering the green roof installation is also monitored. Four different thermometers are used to measure the temperatures in different points of the roofs and a system of two rain barrels and two pressure sensors allows to collect and compare the rainwater coming from the green and the original roofs. Such an installation, differently from many others, has the advantage to allow a complete characterization of the potential benefits of a multilayer green roof through a comparison of the rainwater released by the two roof configurations at a rainfall event scale.

The study provides the preliminary results arising from the analysis of the two roof configurations' response to a series of rainfall events characterized by different duration and intensity. 
